DOI: 10.12957/demetra.2017.26214

\title{
Programa de Educação pelo Trabalho para a Saúde (PET-Saúde) e a formação do nutricionista num campus de interiorização
}

\section{The Brazilian Education through Work for Health Program (PET-Saúde) and education of nutritionists on a satellite campus}

Ana Eliza Port Lourenço'

Amábela de Avelar Cordeiro'

Jane de Carlos Santana Capelli²

Renata Borba de Amorim Oliveira'

Priscila Vieira Pontes ${ }^{2}$

Maria Fernanda Larcher de Almeida²

Laís Buriti de Barros

\footnotetext{
1 Universidade Federal do Rio de Janeiro, Núcleo de Estudos Plurais em Educação, Alimentação e Humanidades - NESPERA. Campus UFRJ-Macaé Professor Aloísio Teixeira. Macaé-RJ, Brasil.

${ }^{2}$ Universidade Federal do Rio de Janeiro, Curso de Nutrição. Campus UFRJ-Macaé Professor Aloísio Teixeira. Macaé-RJ, Brasil.

Correspondência / Correspondence

Ana Eliza Port Lourenço

E-mail: aelourenco@gmail.com
}

\section{Resumo}

Objetivos: Tendo como enfoque a formação do nutricionista, este artigo analisa a experiência de um grupo do Programa de Educação pelo Trabalho para a Saúde (PET-Saúde), da Universidade Federal do Rio de Janeiro, campus UFRJ-Macaé, vigência 2012-2014. Metodologia: O grupo desenvolveu atividades sobre nutrição na rede municipal de saúde. A concepção do PETSaúde se deu no âmbito da extensão universitária, entendida como parte integrante e indissociável do ensino superior. As atividades de formação da equipe basearam-se no referencial teórico freiriano sobre problematização-reflexão. Foi feita análise de conteúdo para avaliar depoimentos de membros do grupo sobre a vivência no PET-Saúde. Resultados e discussão: O ponto forte da experiência foi o aprendizado fundamentado na prática e na troca de saberes, que beneficiou a formação de todos os atores. Tais benefícios contribuem para a formação do nutricionista, pois estreitam a distância entre o ensino acadêmico e a prática profissional. A experiência favoreceu maior engajamento social, autonomia, protagonismo, criticidade e alargamento da visão do acadêmico sobre as questões de saúde e nutrição no âmbito do Sistema Único de Saúde. Precisa-se pensar nos desdobramentos da experiência do PET-Saúde, em especial diante do atual cenário de transformação do ensino superior brasileiro. Conclusões: Ajustes curriculares e pedagógicos na formação do nutricionista podem ser pensados à luz desta experiência, de maneira a melhor incorporar demandas sociais e promover educação com potencial transformador. Nesse sentido, a experiência contribui 
com o movimento contra-hegemônico ao modelo de formação profissional voltado para o mercado capitalista.

Palavras-chave: Educação Superior. Extensão Comunitária. Nutrição em Saúde Pública. Promoção da Saúde. Hábitos Alimentares.

\section{Abstract}

Objectives: With a focus on nutritionists' education, this article analyzes the experience of a team of the Education through Work for Health Program (PET-Saúde) in the Federal University of Rio de Janeiro, Macaé Campus, effective between 2012 and 2014. Methodology: This team developed activities about nutrition in the municipal health system. PET-Saúde was created in the context of university extension, and it is understood as an integral and inseparable part of higher education. Educational and training activities for the team were based on the Freirian theoretical framework on problematization-reflection. Content analysis was performed to assess members' testimonials about their experience in PET-Saúde. Results and discussion: Practice-based learning and knowledge exchange were the main experience benefits to the education of all group members. These benefits contribute to nutritionists' education, because they narrow the distance between academic education and professional practice. This experience fostered greater social engagement, autonomy, leadership, criticality and broadening of student's perception on health and nutrition issues within the Brazilian Health System. One needs to think about the repercussions of the experience of PET-Saúde, especially given the current scenario of adjustment of Brazilian higher education. Conclusions: Curricular and pedagogical changes in nutritionists' education may be rethought, based on this experience, in order to better incorporate social demands and promote education with a transformative potential. In this sense, this experience contributes to the no-hegemonic movement against the professional education model focused on the capitalist market.

Key words: Education Higher. Community-Institutional Relations. Nutrition Public Health. Health Promotion. Food Habits. 


\section{Introdução}

O Programa de Reorientação da Formação Profissional em Saúde (Pro-Saúde), uma parceria entre os ministérios da Educação e da Saúde, visa redirecionar a formação de profissionais de saúde para fortalecer a integração entre instituições de ensino superior (IES), o serviço público de saúde e a comunidade, com vistas à consolidação do Sistema Único de Saúde (SUS). ${ }^{1}$ Para isso, o Pro-Saúde oferece recursos financeiros para as IES, bem como bolsas por meio do Programa de Educação pelo Trabalho para a Saúde (PET-Saúde). Ao aproximar a formação acadêmica da prática profissional, espera-se induzir mudanças curriculares e incentivar o aprendizado discente para que ultrapasse os limites do território universitário, aproximando-se da rotina dos serviços e das necessidades da sociedade. Busca-se, assim, superar uma formação tecnicista e fragmentada e direcionar a formação contemporânea no sentido de atender às demandas de recursos humanos para o SUS e de contribuir para melhorias concretas nas condições de vida da população.

São notórios os avanços de consolidação do SUS ao se comparar a situação atual com os primórdios de sua implantação no início da Reforma Sanitária Brasileira, na década de 1980.2 Ocorreram importantes progressos no que diz respeito à transição do modelo hegemônico centrado na assistência curativa e hospitalar para um modelo de assistência integral à saúde, que prevê em seu cerne o cuidado humanizado, a promoção da saúde e a prevenção de agravos. Contudo, a exequibilidade do SUS ainda apresenta ampla agenda de desafios, como: intensificar a participação e o controle social, fortalecer a regionalização e, sobretudo, adequar a formação profissional em saúde de maneira a atender às necessidades desse novo modelo de atenção. ${ }^{3,4} \mathrm{O}$ Pro-Saúde e o PET-Saúde são iniciativas governamentais para superar tais desafios por meio da graduação de profissionais mais preparados para atuar no SUS, em especial na Atenção Primária à Saúde. Nesse sentido, o desenvolvimento de grupos PET-Saúde constitui a base para novas diretrizes curriculares como parte de um processo histórico, dinâmico e coletivo de avaliação e aprimoramento, tanto da formação superior em saúde, como das políticas e programas que orientam essa formação. ${ }^{5,6}$

O nutricionista é um profissional de saúde que tem como objeto de trabalho a alimentação humana, seja na dimensão individual ou coletiva. ${ }^{7}$ As orientações curriculares para a formação do nutricionista vêm sendo influenciadas por mudanças diversas ocorridas no ensino superior brasileiro e pela própria reorganização das práticas de saúde advindas da criação do SUS. ${ }^{8}$ Sobretudo a implantação da Estratégia de Saúde da Família (ESF), ${ }^{9}$ bem como dos Núcleos de Apoio à Saúde da Família (NASF) ${ }^{10}$ apresenta importante relação com a formação do nutricionista, pois prevê a realização, pela equipe multidisciplinar de saúde, de uma gama de ações sob a temática da Alimentação e Nutrição.

As Diretrizes Curriculares Nacionais para o Curso de Nutrição, propostas em 2001, enfatizam a necessidade de uma formação generalista, humanista, crítica e reflexiva, que permita ao nutricionista desenvolver competências para integrar as equipes multiprofissionais de saúde. ${ }^{11}$ 
Todavia, existem dificuldades para o alcance dessa formação diferenciada. Entre essas, destaca-se o fato de a própria identidade profissional do nutricionista ainda se encontrar em construção $0^{12} \mathrm{e}$ existirem lacunas de formação referentes a assuntos pouco abordados nos cursos de graduação, mas que seriam essenciais para a atuação no SUS. ${ }^{8,13-15}$

A extensão universitária consiste em processo científico, educativo e cultural, que se articula com a pesquisa e o ensino e possibilita a transformação social por meio do vínculo e da troca de saberes que ocorre entre universidade e sociedade. ${ }^{16}$ Logo, a extensão desempenha importante papel no atual processo de reforma universitária, devido ao seu potencial para contribuir com uma educação mais crítica e pertinente às demandas sociais, em especial àquelas relacionadas ao aprimoramento do SUS. ${ }^{17}$ Ressalta-se que, nos contextos de interiorização, a extensão pode estar especialmente fortalecida, pois a criação de novos campi no interior do país pauta-se na participação das universidades no desenvolvimento regional, por meio de estreita integração político-social com a comunidade, do aprimoramento da formação profissional nas localidades e da condução de pesquisas e ações de interesse regional. ${ }^{18}$

O campus UFRJ-Macaé Professor Aloísio Teixeira (campus UFRJ-Macaé) é um campus avançado da Universidade Federal do Rio de Janeiro (UFRJ), que integra as ações nacionais de interiorização do ensino superior, promulgadas no governo de Luís Inácio Lula da Silva. Em constante expansão, desde sua implantação, em 2006, visa se consolidar na região pelo tripé pesquisa-ensino-extensão. Desde 2009, alberga quatro cursos de graduação na área de saúde, em especial o de Nutrição.

Tendo como enfoque a formação do nutricionista, o objetivo deste artigo é analisar a experiência de um grupo PET-Saúde do campus UFRJ-Macaé que trabalhou a temática da Nutrição.

\section{Metodologia}

\section{Contexto e escopo do grupo PET-Saúde em Nutrição}

O campus UFRJ-Macaé tem construído uma história de integração com a rede municipal de saúde por meio de projetos de pesquisa e extensão. Em agosto de 2012, inseriu-se no Pro-Saúde, constituindo quatro grupos PET-Saúde. Entre esses, destaca-se o grupo foco do presente artigo, que trabalhou a temática da Nutrição, com ênfase em Promoção da Alimentação Saudável (PAS) e Prevenção de Doenças e Agravos Não Transmissíveis (DANT) na rede de saúde de Macaé. Todas as atividades do grupo aconteceram entre agosto de 2012 e dezembro de 2014.

Esse grupo, conforme as normas para composição de equipes PET-Saúde, ${ }^{1}$ foi composto por 12 discentes bolsistas e três voluntários, incluindo 12 graduandos em Nutrição, um em Medicina e dois em Enfermagem e Obstetrícia. O Pro-Saúde também forneceu bolsa de preceptoria, que no grupo em foco foi para seis nutricionistas do município, atuantes na Atenção Primária à Saúde 
e na Coordenadoria da Área Técnica de Alimentação e Nutrição de Macaé (CATAN). No que se refere à tutoria, havia no grupo uma docente tutora formal, porém a prática de trabalho ocorreu de forma compartilhada entre sete docentes nutricionistas do Curso de Nutrição do campus UFRJMacaé, atuantes em diferentes áreas do conhecimento.

O projeto do grupo PET-Saúde em Nutrição teve como escopo três principais linhas de atuação: 1) Formação de graduandos em atividades de extensão junto a nutricionistas e outros profissionais da rede de saúde; 2) Promoção e atualização do conhecimento de profissionais de saúde sobre PAS e prevenção de DANT; e 3) Desenvolvimento de ações sobre PAS e prevenção de DANT junto à comunidade. Dentro de cada uma dessas linhas, foram desenvolvidas atividades vinculadas a quatro subprojetos constituintes do grupo PET-Saúde em Nutrição, a saber: (I) O Sistema de Vigilância Alimentar e Nutricional (SISVAN) e as ações de PAS; (II) Compreensão dos rótulos de alimentos e PAS; (III) Estratégias promotoras de aleitamento materno e alimentação complementar e a prevenção de DANT na vida adulta; e (IV) Prevenção e controle de DANT através de práticas dietéticas.

\section{Atividades desenvolvidas}

No que se refere à primeira linha de atuação, a formação dos graduandos ocorreu por meio de atividades semanais em campo prático, participando da rotina de trabalho das preceptoras. No âmbito de cada subprojeto, os alunos desempenharam tarefas diversas, relacionadas ao atendimento aos usuários, aprimoramento do serviço e planejamento e execução de ações de caráter educativo em saúde e nutrição. Por exemplo, no subprojeto I, os alunos participaram da rotina da CATAN e auxiliaram no aprimoramento de registros do SISVAN. No contexto do subprojeto II, os discentes acompanharam o trabalho das nutricionistas em ESF e construíram dinâmicas educativas para trabalhar o tema da rotulagem de alimentos e PAS junto aos usuários. Em termos de formação, não apenas dos discentes, mas de todo o grupo PET-Saúde em Nutrição, destaca-se a realização mensal de oficinas e seminários para discussão de literatura e para os subprojetos compartilharem entre si as atividades que estavam desenvolvendo.

Na segunda linha de atuação do grupo, voltada para a formação de profissionais de saúde, sobressaem-se ações desenvolvidas pelo subprojeto III. Ocorreu, por exemplo, a capacitação de profissionais da rede municipal de saúde, utilizando uma mostra de vídeos sobre alimentação infantil. Realizou-se também um minicurso sobre aleitamento materno e alimentação complementar, tendo como públicos-alvo profissionais de saúde do município, graduandos da área da saúde e a comunidade em geral. Ainda que direcionados para público interno ao grupo, cabe mencionar a realização de dois seminários de formação de preceptores, quando se discutiu o papel da preceptoria na Educação Superior. 
No âmbito da terceira linha de atuação, voltada para ações junto à comunidade, foram várias e diversas as atividades educativas sobre PAS e prevenção de DANT desenvolvidas pelos quatro subprojetos nos locais de prática e em eventos em espaços públicos abertos à comunidade. Cita-se como exemplo a realização pelo subprojeto IV de diagnóstico situacional sobre DANT seguido por oficinas culinárias com adultos e idosos usuários de ESF e/ou participantes do Programa de Atenção Integral à Saúde do Idoso (PAISI). Ressalta-se também a produção de materiais educativos impressos, que foram distribuídos em eventos oportunos, como campanhas de vacinação.

\section{Referencial teórico}

A concepção do grupo PET-Saúde em Nutrição foi estabelecida no âmbito da extensão universitária, entendida como um processo dinâmico de interação entre academia e sociedade, que promove um aprendizado singular para todos os atores nele envolvidos, conforme favorece a troca de saberes. ${ }^{16}$ A extensão foi, por conseguinte, tida como parte integrante e indissociável do ensino superior, sendo necessária, sobremaneira, para o fortalecimento da formação em saúde.

A proposta educativa adotada na condução das três linhas de atuação do grupo foi determinada com base no referencial freiriano, que enfatiza a importância da problematização e destaca o ser humano como protagonista do processo de conhecimento. ${ }^{19}$ Tanto nas atividades voltadas para a formação dos integrantes do grupo, como naquelas direcionadas para profissionais de saúde e para a população em geral, buscou-se adotar o diálogo horizontal, favorecendo a troca de experiências e a participação democrática.

Sobretudo na linha 1, que concerne à formação dos discentes do grupo PET-Saúde em Nutrição, pressupôs-se que as habilidades cognitivas são construídas por meio de exploração da realidade, em especial diante de situações-problema. De forma análoga à problematização-reflexão proposta por Freire, ${ }^{19}$ esperava-se que os graduandos, por meio da identificação de problemas durante a vivência prática, refletissem sobre PAS e prevenção de DANT na rede de saúde, bem como sobre sua própria formação profissional.

\section{Estratégias utilizadas para a avaliação da experiência}

Para o presente estudo, foram utilizados os dados qualitativos relativos a uma avaliação somativa acerca do andamento do grupo PET-Saúde em Nutrição, realizada com os membros da equipe, após um ano do início do Programa. Foi solicitado aos mesmos que fizessem um registro escrito individual sobre sua vivência no Programa. Para orientar a escrita, foram estabelecidas três perguntas norteadoras: (1) Como tem sido a vivência do que você tem feito no PET-Saúde?; (2) O que tem sido positivo e o que tem sido negativo?; e (3) Que propostas você teria para futuras experiências? 
Realizaram o registro 16 integrantes da equipe, sendo nove alunos, quatro preceptoras e três docentes. Os textos foram analisados de modo qualitativo por meio de análise temática do conteúdo. ${ }^{20}$ Uma das autoras fez leitura flutuante do material, seguida por exploração em profundidade. Foram identificadas unidades temáticas de análise, que foram organizadas em categorias. Essas foram interpretadas com base no cenário teórico delineado a priori, em especial no que se refere aos objetivos do Pro-Saúde e à formação profissional do nutricionista. Como forma de validação, a análise foi apreciada pelos membros da equipe em seminário interno organizado para esse fim.

Foram respeitados todos os procedimentos éticos para o desenvolvimento das atividades do grupo PET-Saúde em Nutrição. A proposta obedeceu às exigências para credenciamento de projetos de extensão na UFRJ, bem como os regulamentos éticos previstos pelo Pro-Saúde e pelo PET-Saúde. Dentre esses, cabe enfatizar a anuência e concordância da Secretaria Municipal de Saúde de Macaé e da IES para com o desenvolvimento da proposta.

\section{Resultados e Discussão}

\section{Vivência no PET-Saúde e a formação do graduando de Nutrição}

Aproximar o ensino acadêmico da prática profissional consiste em objetivo-chave do PET-Saúde, que caminha plenamente de acordo com as diretrizes curriculares recentes para a formação em Nutrição. Neste estudo, a experiência em campo foi considerada de extrema importância tanto pelos alunos, quanto pelas preceptoras e professoras, sendo citada por todos os respondentes.

Uma das alunas de Nutrição comentou que "a vivência (no PET-Saúde) tem sido ótima, pois além de base teórica estamos tendo contato com a prática, podendo relacionar ao que realmente acontece no município de Macaé" (Aluna A). Tal reconhecimento por parte dos alunos da relevância para sua formação da inserção em campo prático também esteve presente em grupos PET-Saúde de outras IES no país. ${ }^{21-24}$ Por exemplo, graduandos de Medicina de IES de Curitiba comentaram sobre a relevância de conhecer na prática as limitações do SUS e de aprender a trabalhar tanto com elas quanto com as condições adversas de vida dos usuários. ${ }^{24}$ Para graduandos na área da saúde de IES da Bahia e de Pernambuco, a vivência nos serviços os permitiu entender a estrutura da rede de atenção à saúde e pensar sobre as reais condições do serviço para atender às demandas locais. ${ }^{23}$

Esse maior contato do discente com a realidade do município e com a rotina no SUS contribui para uma formação socialmente engajada, fortemente desejável ao nutricionista e a todo profissional de saúde. Tendo em vista que se espera que os profissionais de saúde promovam modificações na forma como ocorre a atenção à saúde na esfera do SUS, cabe resgatar a concepção problematizadora e libertadora da educação. ${ }^{19}$ Ao entrar em contato entre si e com a realidade circundante, os 
educandos se deparam com problemas que os estimulam a refletir, favorecendo a realização do fenômeno ação-transformação. Nesse sentido, pode-se dizer que a vivência no PET-Saúde colabora para instigar a reflexão dos alunos sobre as questões de saúde e nutrição no âmbito do SUS, bem como sobre seu próprio papel enquanto acadêmico inserido nesse cenário.

A vivência prática é capaz de fortalecer o significado daquilo que se aprende e de valorizar o educando como ator participativo do processo de aprendizagem. Essa valorização pode ser percebida, por exemplo, no seguinte comentário de uma das alunas do grupo: "A vivência é gratificante, pois me sinto útil e capaz de ajudar a mudar um pouco da realidade de Macaé (...)" (Aluna B). Ressalta-se, de acordo com Freire, ${ }^{19}$ que o protagonismo do educando, sendo esse sujeito dono do seu pensar e livre para compartilhar sua visão de mundo, é primordial para que a educação gere criticidade, autonomia e emancipação. A experiência no PET-Saúde em Nutrição favoreceu o protagonismo do estudante, o que vai de acordo com o tipo de profissional que se pretende para o SUS, em especial nas equipes multidisciplinares.

Entraves relacionados à atuação do nutricionista nas equipes multidisciplinares de saúde têm sido abordados em alguns estudos. ${ }^{12,15,25,26}$ Discute-se principalmente sobre dificuldades relacionadas à autonomia profissional ${ }^{27} \mathrm{e}$ sobre elementos que poderiam estar mais presentes na formação em Nutrição para favorecer o trabalho em equipes. Entre esses, ressalta-se o potencial de experiências interdisciplinares durante a graduação. Segundo Boog, ${ }^{26}$ essas auxiliam sobremaneira uma formação mais coerente com o que se espera que o nutricionista desenvolva no campo da Saúde Coletiva. Cabe lembrar que a assistência individualizada, centrada na figura do médico, é um desafio a ser superado nos serviços de saúde. Assim, a participação no PET-Saúde foi uma oportunidade ímpar, pois estimulou a interação de graduandos de Nutrição com outros de diferentes cursos e com distintos profissionais dos serviços, num contexto interdisciplinar.

A troca de saberes proporcionada por tal contexto interdisciplinar, sobretudo o in lócus, foi considerada pelos discentes respondentes deste estudo uma possibilidade singular de amadurecimento pessoal e acadêmico e uma forma de ampliação da sua visão sobre as funções do profissional de saúde na rede e dentro dos programas governamentais. Tal alargamento da visão do acadêmico também foi apontado por Souza et al.., ${ }^{28}$ que observaram que a participação de alunos da Universidade Federal de Pelotas no PET-Saúde fortaleceu a crítica reflexiva, auxiliando os discentes na construção de seu perfil profissional.

A criticidade na formação faz-se especialmente necessária no caso do nutricionista, uma vez que o perfil e a própria identidade profissional encontram-se em processo de amadurecimento. ${ }^{12}$ O escopo de atuação do nutricionista ainda não é plenamente claro nem para a sociedade em geral nem para os profissionais de saúde e, por vezes, nem mesmo para os próprios nutricionistas. Conhecimentos e ações de nutrição e PAS têm reconhecida importância na prevenção de DANT e na promoção da saúde e, mormente desde o final da década de 1990, encontram-se valorizados 
nos serviços de saúde. ${ }^{29,30}$ Todavia, o espaço ocupado pelo nutricionista na aplicação desses conhecimentos é difuso, mesclado com a atuação de outros profissionais, da área de saúde e de fora dela, o que dificulta a definição de sua identidade profissional e sua efetiva integração na equipe de saúde.

Isso se deve em parte à amplitude de dimensões, para além da biológica, que permeia a alimentação humana. Estudos advindos principalmente do campo da Antropologia ${ }^{31}$ têm destacado o intrincado conjunto de aspectos sociais, culturais, econômicos, entre outros, que perpassam a alimentação. Logo, faz-se necessária uma formação em Nutrição que amplie a visão do nutricionista sobre a alimentação, superando o olhar estritamente biomédico. ${ }^{14,15}$ Por meio da presente experiência, percebeu-se o potencial do PET-Saúde para essa formação mais ampliada, uma vez que, ao proporcionar reflexão constante sobre a teoria junto à prática, a vivência permite ao estudante melhor entendimento dos condicionantes do processo saúde-doença e, sobretudo, da diversidade que permeia o comer, o alimentar e o nutrir.

Em termos curriculares, Recine et al. ${ }^{14}$ avaliaram cursos de graduação em Nutrição em todo o país e identificaram que a tradicionalmente chamada Nutrição e Saúde Pública, área temática de maior interface com as perspectivas de formação do nutricionista para o SUS, tem ocupado, no máximo, 30\% da carga horária total dos cursos. Esses autores comentaram ainda sobre a necessidade de a formação ter maior ênfase em temas interdisciplinares, não exclusivos da saúde, como Segurança Alimentar e Nutricional, e Saúde na Escola. Mota, Oliveira e Boog ${ }^{32}$ avaliaram a apresentação na internet de Cursos de Nutrição no Brasil e observaram o predomínio de informações sobre o mercado de trabalho em Nutrição. Características profissionais valorizadas nas diretrizes curriculares atuais, como humanização e comprometimento do nutricionista para com as transformações sociais, pouco apareceram nos sites.

Tal estudo remete ao fato de que a formação que se deseja para o SUS caminha em movimento contra-hegemônico em relação à formação produtivista, fragmentada, conduzida sob a lógica do capital humano e da empregabilidade. ${ }^{33} \mathrm{~A}$ agenda política atual para superação das dificuldades de consolidação do SUS, expressa no Pacto pela Saúde, clama por mudanças na formação profissional. ${ }^{3}$ No entanto, consiste incontestável desafio contribuir para a negação do projeto capital e, concomitantemente, vislumbrar possibilidades contra-hegemônicas para a formação em saúde.

Os Cursos de Nutrição carecem de modificações que estimulem a capacidade analítica do estudante acerca dos problemas nutricionais, contextualizados nas diferentes perspectivas abarcadas pela alimentação. Em favor da desejada educação transformadora, é preciso ampliar nos currículos a discussão sobre temas, como: políticas de saúde, políticas de ciência e tecnologia, capitalismo e mercantilização do corpo humano e da saúde, e politecnia em saúde..$^{15,33,34}$ Além disso, os projetos pedagógicos dos cursos devem destacar o trabalho em saúde como uma prática social, humanista e cidadã. 


\section{O PET-Saúde e a formação do nutricionista para além da graduação}

Ninguém educa ninguém, como tampouco ninguém se educa a si mesmo: os homens se educam em comunhão, mediatizados pelo mundo (Freire, p. 79). ${ }^{19}$

É oportuno citar aqui esse célebre pensamento de Paulo Freire, que remete à integração entre os diferentes atores, num cenário de aprendizado mútuo e simultâneo, essencial para a educação libertadora do ser humano. Tal integração e a decorrente troca de saberes entre os membros da equipe, e dessa com a comunidade, foram consideradas o ponto mais forte da experiência neste estudo, que enriqueceu a formação de todo o grupo. A relação entre os sujeitos também foi abordada por Fonseca e Junqueira, ${ }^{35}$ com base na vivência de tutores de equipes PET-Saúde da Universidade de São Paulo (USP). Esses autores apontaram a existência de relações "amigáveis", "muito ricas" e a ausência de uma rígida hierarquia como fatores fundamentais para o bom desenvolvimento do Programa.

A forte integração e a construção de vínculos interpessoais no PET-Saúde em Nutrição podem ter sido facilitadas pela curta distância física entre as localidades de prática e a IES em Macaé. Destaca-se que, quando comparado com grandes centros, Macaé é um município de médio porte, com população estimada, em 2010, pelo Censo nacional, em aproximadamente 206 mil habitantes, contando com 83 estabelecimentos de saúde do SUS. Já em cidades de maior porte, como Cuiabá, por exemplo, a distância entre a IES e as unidades de saúde foi considerada um ponto negativo para o desenvolvimento do PET-Saúde, devido às unidades se situarem na periferia, dificultando o acompanhamento semanal dos tutores. ${ }^{36}$

Os vínculos interpessoais entre os atores em Macaé incluíram tanto os discentes, quanto as preceptoras e as docentes. Uma das professoras da tutoria comentou que "o contato com as preceptoras tem me aproximado da prática profissional. Percebo que isso pode me ajudar a ser uma professora melhor" (Professora A). Essa fala salienta que, apesar do Pro-Saúde focar a formação na graduação, pode beneficiar também a formação dos professores envolvidos. Esses têm a oportunidade de refletir sobre seu papel como educadores conforme revisitam práticas da atuação do nutricionista e interagem com alunos e preceptores. Benefícios do PET-Saúde para a docência foram também comentados por tutores da USP, ${ }^{35}$ que destacaram que a experiência no Programa os estimulou a refletir sobre suas práticas pedagógicas e sobre as grades curriculares dos cursos.

Ao estimular o repensar do professor sobre o exercício da docência, a experiência no PET-Saúde traz à tona questionamentos sobre a formação dos docentes que lecionam nos cursos de graduação em Nutrição. ${ }^{32,37}$ Em linhas gerais, a docência em Nutrição tem sido exercida por professores com expertise em suas áreas específicas, porém com pouca, ou mesmo nenhuma, formação pedagógica. 
Fala-se em redirecionar a formação do graduando da saúde, mas para isso, além de modificar currículos e conteúdos, é preciso rever a formação docente e as práticas pedagógicas necessárias para esse redirecionamento. ${ }^{34,38}$

A experiência no PET-Saúde em Nutrição também toca a formação do nutricionista preceptor, que pode repensar sua atuação profissional e aprender conforme convive com os professores e alunos. Um exemplo desse repensar pode ser percebido no seguinte comentário de uma preceptora atuante no NASF sobre suas expectativas acerca do Programa:

(...) esperava crescer enquanto profissional e me aproximar novamente da universidade, uma vez que trabalhando, ficamos sem tempo para estudar e nos distanciamos um pouco desta, e com isso ser um instrumento para transmitir à comunidade aquilo que foi estudado (Preceptora A).

A possibilidade de, por meio da participação no PET-Saúde em Nutrição, aprimorar a si mesmo e ao serviço, de forma melhor atender a população, esteve notoriamente presente nas narrativas das preceptoras. Foi mencionada a vontade de "contribuir de forma direta para o planejamento e aplicação de melhorias no serviço" (Preceptora B), "enriquecer tecnicamente a prática profissional" (Preceptora A) e "estimular a mudança da rotina de trabalho do profissional preceptor" (Preceptora C). A reflexão sobre o próprio processo de trabalho também foi identificada entre preceptores do PET-Saúde da Faculdade de Medicina de Botucatu ${ }^{39}$ e da Universidade Federal do Mato Grosso do Sul (UFMS). ${ }^{22}$ Destaca-se que na Universidade Federal de Alagoas, preceptores de grupos PETSaúde do Curso de Enfermagem consideraram que a oportunidade de mostrar seu trabalho aos estudantes reforçou seu sentimento de valorização profissional. ${ }^{40}$

Tais experiências de preceptoria remetem à complexa discussão sobre Educação Permanente na área da saúde. ${ }^{41}$ A educação permanente do nutricionista para o SUS poderia caminhar na mesma linha de educação discutida no âmbito da graduação, favorecendo criticidade e protagonismo. Principalmente a atuação no NASF exige profissionais capazes de desenvolver ações de caráter interdisciplinar, intersetorial, ético, resolutivo, longitudinal, acolhedor, com vínculo e responsabilização. ${ }^{42}$

Obviamente, essa formação não é simples de ser alcançada, sendo necessário trabalhar, tanto na graduação, quanto na pós-graduação e no domínio da Educação Permanente, a gama de temas associados ao que se espera do nutricionista em Saúde Coletiva. Uma publicação recente de destaque nessa linha é o Consenso sobre Habilidades e Competências do Nutricionista no Âmbito da Saúde Coletiva, ${ }^{42}$ que traz informações capazes de orientar os docentes em relação às necessidades curriculares para atender às demandas do SUS. 


\section{Dificuldades da experiência do PET-Saúde em Nutrição}

No que toca os pontos negativos da experiência no PET-Saúde em Nutrição, todos os respondentes do presente estudo comentaram sobre dificuldades de infraestrutura física e organizacional. Por exemplo, as unidades de saúde não comportavam o conjunto de alunos e profissionais. Além disso, a estrutura de laboratórios e salas do Curso de Nutrição em Macaé é precária e está em constante reformulação. Sendo assim, não havia local adequado para reuniões de equipe nem espaço para guardar os materiais dos projetos. Dificuldades estruturais semelhantes foram vivenciadas por grupos PET-Saúde de outras IES. ${ }^{21,22,39}$

Nepomuceno, ${ }^{43}$ dissertando sobre o processo de interiorização da UFRJ, já havia apontado problemas estruturais no campus UFRJ-Macaé, notadamente no que diz respeito à disponibilidade de salas nos prédios. É pertinente comentar que, em decorrência dos incentivos financeiros governamentais para expansão do ensino superior, em um curto período de tempo foram criados diversos campi no país, ${ }^{18}$ principalmente após 2007, por meio do Programa de Reestruturação e Expansão das Universidades Federais (REUNI). ${ }^{44}$ Houve rápida implantação de novos cursos, mesmo quando sua estrutura de planejamento ainda não estava totalmente pronta, como foi o caso na Universidade Federal da Paraíba ${ }^{45}$ e na UFRJ. ${ }^{43}$

Na vigência do PET-Saúde em Nutrição, o campus UFRJ-Macaé ainda não era unidade gestora e, portanto, dependia de outras unidades da UFRJ para realizar compras relacionadas ao ProSaúde. Isso implicou morosidade, ou mesmo incapacidade, para realizar as compras previstas. Consequentemente, parte das ações planejadas teve que ser cancelada por falta de recursos financeiros. Outra dificuldade, que também tem relação com a precocidade do campus UFRJ-Macaé, foi que seu número de docentes e técnicos apresentava-se francamente aquém do necessário na época do Programa, gerando sobrecarga de trabalho para os professores.

No que se refere à logística de trabalho, a IES e o serviço estavam, de certa forma, despreparados para receber o PET-Saúde. Por exemplo, as preceptoras destacaram que, mesmo com o propósito de ajudar o serviço, o Programa era visto como "trabalho extra" em alguns órgãos municipais. Ressalta-se que o ritmo de trabalho no serviço de saúde difere consideravelmente daquele do acadêmico. Conciliar o rigor de planejamento previsto na academia com as diversas demandas e curtos prazos impostos pelo serviço constituiu uma limitação para a concretização das atividades.

A incompatibilidade de agendas por vezes inviabilizava o trabalho em equipe. Quando possível, as atividades do grupo tiveram que acontecer no turno da noite para permitir a presença de todos, o que foi percebido como cansativo e pouco produtivo. Além disso, devido às atividades do PET-Saúde não estarem totalmente articuladas com aquelas regulares da graduação, muitas vezes havia tarefas concomitantes, prejudicando o engajamento pleno dos alunos no Programa. 
Dificuldades de incongruência de horários também foram observadas em outras IES. ${ }^{22,23,35,39}$ No caso da UFMS, reuniões no horário de almoço ou noturno desmotivaram alguns alunos, que optaram por abandonar o Programa. ${ }^{22}$

A articulação do PET-Saúde com as atividades regulares dos cursos de graduação consiste em uma das metas do Pro-Saúde, ${ }^{1}$ certamente uma das mais difíceis de ser alcançada, e caso fosse, possivelmente conseguiria minimizar as dificuldades supracitadas. Trata-se de uma meta audaciosa, pois inclui repensar os currículos, não apenas de um curso, mas de todos aqueles envolvidos na interdisciplinaridade proposta pelo Programa.

Mudanças nos cursos de graduação e no serviço de saúde pautadas na experiência do PETSaúde são intrincadas e de longo prazo, envolvendo entraves em diferentes níveis, distanciados da realidade dos participantes do Programa. Esse distanciamento pode ser considerado um aspecto negativo da vivência, como comentou uma das alunas de Nutrição:

Acredito que tem sido negativa a falta de esclarecimento em relação à aplicação do que faremos no campo prático. (...) Como o resultado do nosso projeto será passado para os demais discentes/docentes/profissionais? (...) Como ocorre a utilização do mesmo pelo Ministério da Saúde? A falta de esclarecimento para todos os participantes em relação a isso tem sido muito negativa (...) (Aluna D).

Esse comentário traz luz a uma reflexão mais ampla sobre o PET-Saúde e sobre como serão os desdobramentos das ações. Nesse sentido, é pertinente pensar em propostas de divulgação das experiências do PET-Saúde na sociedade, nos serviços e na universidade, com envolvimento da coordenação dos cursos, a fim de promover esclarecimento e articulação, beneficiando o alunato como um todo.

\section{Considerações finais}

Esta experiência do PET-Saúde em Nutrição no campus UFRJ-Macaé trouxe importante ensinamento sobre a potencialidade do Programa enquanto caminho para redirecionar a formação em Nutrição, aproximando o graduando do campo prático na rede SUS. A equipe alcançou os objetivos de oferecer formação diferenciada aos seus integrantes e de aproximar a universidade dos serviços de saúde e da comunidade. Certamente, o Programa oportunizou aos discentes participantes, bem como às nutricionistas preceptoras e professoras, uma vivência de intenso aprendizado, pautado na prática profissional e na troca de saberes. Todavia, permanece o questionamento sobre como serão beneficiados os discentes e profissionais que não integraram o Programa. Essa é uma questão central para pensar sobre a repercussão do PET-Saúde e a formação em Nutrição. Como as experiências em nível local orientarão o redirecionamento da formação 
nos diferentes Cursos de Nutrição e da área de saúde? Compartilhar vivências de grupos PETSaúde com a comunidade acadêmica parece ser um caminho promissor para estimular reflexão e instigar mudanças.

As ações do PET-Saúde em Nutrição voltadas para a sociedade e para o serviço conseguiram ser desenvolvidas a contento, superando dificuldades logísticas e financeiras. Foram desenvolvidas atividades educativas com a comunidade e ações junto aos serviços, que visavam ao aprimoramento dos mesmos. Vale refletir, porém, se essas ações foram apenas pontuais ou poderiam ocorrer de maneira continuada, pois a continuidade depende de distintos fatores relacionados aos serviços na rede, que estão fora da governabilidade do grupo PET-Saúde. A viabilidade e o interesse pela regularidade das ações precisariam ser discutidos com gestores, profissionais de saúde, bem como com os usuários da rede.

A ausência de agenda comum para realizar os trabalhos em equipe e a dificuldade em conciliar as tarefas do Programa com aquelas do currículo formal consistiram em marcantes desafios vivenciados pelo grupo PET-Saúde em Nutrição. Esses poderiam ser minimizados com a vinculação do PET-Saúde como atividade curricular regular.

O ensino superior brasileiro vive um momento inédito de valorização da extensão universitária, em que refletir sobre experiências do PET-Saúde pode ser oportuno. Via o Plano Nacional de Educação de 2014, ${ }^{17}$ o Ministério da Educação estabeleceu como meta que, no mínimo, dez por cento do total de créditos exigidos para a graduação em todos os cursos no ensino superior nacional deverão ser cumpridos pelos alunos em atividades de extensão. Essa determinação levanta ampla discussão no cenário universitário contemporâneo, sobretudo sobre o papel da universidade na formação de profissionais críticos, que atendam às demandas da sociedade, em contraposição a uma formação técnica, voltada para as demandas do mercado capitalista.

Tal discussão caminha em harmonia com os princípios do PET-Saúde, bem como com os resultados da experiência neste texto relatada. Para atender à meta de ampliação da extensão, os cursos da saúde terão que repensar suas estruturas e provavelmente realizar reforma curricular. O Curso de Nutrição do campus UFRJ-Macaé se insere nesse cenário, tendo realizado, desde 2015, seminários internos e reuniões do seu Núcleo Docente Estruturante, para refletir sobre possíveis modificações curriculares. Trata-se de um desafio para o qual a experiência do PET-Saúde em Nutrição tem amplo potencial de contribuição.

Vale salientar que o Curso de Nutrição do campus UFRJ-Macaé já possui por princípio inserir os graduandos nos cenários de prática desde os primeiros períodos. Tal característica inovadora pode ser vista como um passo avante na direção de mudanças curriculares futuras. Além disso, o Curso é ainda jovem, tendo sua primeira turma concluída em 2013. Esse fato pode favorecer a dinâmica das ações de reorientação da formação, pois a matriz curricular não foi plenamente implantada e pode vir a ser pensada à luz da experiência do PET-Saúde em Nutrição. 
De certo que mudanças curriculares são intrincadas e demandam tempo não apenas no sentido de reflexão, mas também na vertente político-burocrática. Pensar em redirecionar a formação profissional em Nutrição abrange lidar com a constante desconstrução e reconstrução de conceitos pelos diferentes atores envolvidos. É um tema que abarca não apenas aspectos educacionais, mas também políticos e sociais, relacionados ao tipo de formação profissional que a sociedade deseja e necessita.

\section{Colaboradores}

Lourenço AEP, Cordeiro AV, Capelli JCS e Oliveira RBA responsabilizaram-se pela concepção e delineamento do estudo. Lourenço AEP responsabilizou-se pela análise dos dados qualitativos. Todas as autoras trabalharam juntas na redação e revisão crítica do manuscrito.

Conflito de Interesses: Os autores declaram não haver conflito de interesses.

\section{Referências}

1. Brasil. Ministério da Saúde. Ministério da Educação. Programa Nacional de Reorientação da Formação Profissional em Saúde - Pro-Saúde: objetivos, implementação e desenvolvimento potencial. Brasília: MS, ME; 2007.

2. Vasconcelos CM, Pasche DF. O Sistema Único de Saúde. In: Campos GWS, Minayo MCS, Akerman M, Drumond-Júnior M, Carvalho YM, organizadores. Tratado de saúde coletiva. $2^{\mathrm{a}}$ ed. São Paulo: Hucitec; 2012. p. 531-562.

3. Brasil. Portaria no 399/GM, de 22 fev. 2006. Divulga o Pacto pela Saúde 2006 - Consolidação do SUS e aprova as diretrizes operacionais do referido. Diário Oficial da União 23 fev. 2006.

4. Carvalho ALB, Souza MF, Shimizu HE, Senra IMVB, Oliveira KC. A gestão do SUS e as práticas de monitoramento e avaliação: possibilidades e desafios para a construção de uma agenda estratégica. Ciênc Saúde Coletiva 2012; 17(4):901-911.

5. Dias HS, Lima LD, Teixeira M. A trajetória da Política Nacional de Reorientação da Formação Profissional em Saúde no SUS. Ciênc. Saúde Coletiva 2013; 18(6):1613-1624.

6. González AD, Almeida MJ. Movimentos de mudança na formação em saúde: da medicina comunitária às diretrizes curriculares. Physis - Revista de Saúde Coletiva 2010; 20(2):551-570.

7. Ypiranga L. Delimitação do objeto de trabalho do nutricionista: subsídios para uma discussão. Saúde em Debate 1990; 29:62-69.

8. Soares NT, Aguiar AC. Diretrizes curriculares nacionais para os cursos de nutrição: avanços, lacunas, ambiguidades e perspectivas. Rev Nutr. 2010; 23(5):895-905. 
9. Brasil. Portaria no 154/GM, de 24 jan. 2008. Cria os Núcleos de Apoio à Saúde da Família - NASF. Diário Oficial da União 4 mar. 2008.

10. Brasil. Portaria no 2.488/GM/MS, de 21 out. 2011. Aprova a Política Nacional de Atenção Básica, estabelecendo a revisão de diretrizes e normas para a organização da Atenção Básica, para a Estratégia Saúde da Família (ESF) e o Programa de Agentes Comunitários de Saúde (PACS). Diário Oficial da União 31 out. 2011.

11. Brasil. Resolução no 5/CNE/CES. Institui as Diretrizes Curriculares Nacionais do Curso de Graduação em Nutrição. Diário Oficial da União 7 nov. 2001.

12. Banduk MLS, Ruiz-Moreno L, Batista NA. A construção da identidade profissional na graduação do nutricionista. Interface - Comunicação, Saúde, Educação 2009; 13(28):111-120.

13. Alvez CGL, Martinez MR. Lacunas entre a formação do nutricionista e o perfil de competências para atuação no Sistema Único de Saúde (SUS). Interface - Comunicação, Saúde, Educação 2016; 20(56):159-169.

14. Recine E, Gomes RCF, Fagundes AA, Pinheiro ARO, Teixeira BA, Sousa JS, et al. A formação em saúde pública nos cursos de graduação de nutrição no Brasil. Rev. Nutr. 2012; 25(1):21-33.

15. Rossoni E, Lampert J. Formação de profissionais para o Sistema Único de Saúde e as Diretrizes Curriculares. Boletim da Saúde 2004; 18(1):87-98.

16. Universidade Federal do Rio Grande do Sul. Fórum de Pró-Reitores de Extensão das Instituições Públicas de Educação Superior Brasileiras. Política Nacional de Extensão Universitária. Porto Alegre: UFRS; 2012. Coleção Extensão Universitária, v.7.

17. Brasil. Lei Federal no 13.005. Aprova o Plano Nacional de Educação - PNE e dá outras providências. Diário Oficial da União 25 jun. 2014.

18. Brasil. Ministério da Educação. Secretaria de Educação Superior (SESu). A democratização e expansão da educação superior no país 2003-2014. Brasília: SESu; 2015.

19. Freire P. Pedagogia do oprimido. 46. ed. Rio de Janeiro: Paz e Terra; 2005.

20. Bardin L. Análise de conteúdo. Lisboa: Edições 70; 1995.

21. Morais FRR, Jales GML, Silva MJC, Fernandes SF. A importância do PET-Saúde para a formação acadêmica do enfermeiro. Trabalho, Educação e Saúde 2012; 10(3):541-551.

22. Oliveira ML, Mendonça MK, Alves-Filho HL, Coelho TC, Benetti CN. PET-Saúde: (In)formar e fazer como processo de aprendizagem em serviços de saúde. Revista Brasileira de Educação Médica 2012; 36(1):105-111.

23. Leal JAL, Melo CMM, Veloso RBP, Juliano IA. Novos espaços de reorientação para formação em saúde: vivências de estudantes. Interface - Comunicação, Saúde, Educação 2015; 19(53):361-71.

24. Albuquerque GSC, Torres AAR, Nascimento B, Martin BM, Gracia DFK, Orlando JMM, et al. Educação pelo trabalho para a formação do médico. Trabalho, Educação e Saúde 2013; 11(2):411-430.

25. Aguiar CB, Costa NMSC. Formação e atuação de nutricionistas dos Núcleos de Apoio à Saúde da Família. Rev Nutr. 2015; 28(2):207-216. 
26. Boog MCF. Atuação do nutricionista em saúde pública na promoção da alimentação saudável. Revista Ciência \& Saúde 2008; 1(1):33-42.

27. Almeida MCP, Mishima SM. O desafio do trabalho em equipe na atenção à Saúde da Família: construindo "novas autonomias" no trabalho. Interface - Comunicação, Saúde, Educação 2001; 9:150-153.

28. Souza PL, Pereira CS, Nogueira MLS, Pereira DB, Cunha GM, Möler FO. Projetos PET-Saúde e Educando para a Saúde: construindo saberes e práticas. Revista Brasileira de Educação Médica 2012; 36(1):172-177.

29. Brasil. Ministério da Saúde. Secretaria de Vigilância em Saúde. Secretaria de Atenção à Saúde. Política Nacional de Promoção da Saúde. Brasília: MS; 2006.

30. Brasil. Ministério da Saúde. Secretaria de Atenção à Saúde. Departamento de Atenção Básica. Política Nacional de Alimentação e Nutrição. Brasília: Ministério da Saúde; 2012.

31. Canesqui AM, Garcia RWD, organizadoras. Antropologia e nutrição: um diálogo possível. Rio de Janeiro: Editora Fiocruz; 2005.

32. Motta DG, Oliveira MRM, Boog MCF. A formação universitária em nutrição. Pro-Posições 2003; 14(1):69-86.

33. Pereira IB. A educação dos trabalhadores da saúde sob a égide da produtividade. In: Matta GC, Lima JCF, organizadores. Estado, sociedade e formação profissional em saúde: contradições e desafios em 20 anos de SUS. Rio de Janeiro: Editora Fiocruz/EPSJV; 2008. p. 393-420.

34. Lopes MCR, Amado LAS. A educação e a formação profissional nas sociedades contemporâneas: problematizando algumas questões. In: Escola Politécnica de Saúde Joaquim Venâncio. Estudos de politecnia e saúde. v. 2. Rio de Janeiro: EPSJV; 2007. p. 229-252.

35. Fonseca GS, Junqueira SR. Programa de Educação pelo Trabalho para a Saúde da Universidade de São Paulo (Campus Capital): o olhar dos tutores. Ciênc. Saúde Coletiva 2014; 19(4):1151-1162.

36. Duarte SJH, Pereira JG, Santos NC, Pereira GAS, Pereira WR. Contribuições do PET-Saúde da família na formação de enfermeiros e médicos no município de Cuiabá, MT. Ciência, Cuidado e Saúde 2012; 11(4):813-819.

37. Costa NMSC. Formação pedagógica de professores de Nutrição: uma omissão consentida? Rev Nutr. 2009; 22(1):97-74.

38. Castanho ME. Professores de Ensino Superior da área da Saúde e sua prática pedagógica. Interface - Comunicação, Saúde, Educação 2002; 6(10):51-61.

39. Cyrino EG, Cyrino APP, Prearo AY, Popim RC, Simonetti JP, Boas PJFV, et al. Ensino e pesquisa na Estratégia de Saúde da Família: o PET-Saúde da FMB/Unesp. Revista Brasileira de Educação Médica 2012; 36(1):92-101.

40. Santos DS, Almeida LMWS, Reis RK. Programa de Educação pelo Trabalho para Saúde: experiência de transformação do ensino e prática de enfermagem. Revista da Escola de Enfermagem da USP 2013; 47(6):1431-1436. 
41. Cessim RB. Educação Permanente em Saúde: desafio ambicioso e necessário. Interface 2005; 9(16):161-177.

42. Recine E. Consenso sobre habilidades e competências do nutricionista no âmbito da Saúde Coletiva. Brasília: Observatório de Políticas de Segurança e Nutrição; 2013.

43. Nepomuceno V. Planejamento de novas estruturas universitárias [dissertação]. Rio de Janeiro: Universidade Federal do Rio de Janeiro; 2009.

44. Brasil. Decreto no 6096, de 24 abr. 2007. Institui o Programa de Apoio a Planos de Reestruturação e Expansão das Universidades Federais - REUNI. Diário Oficial da União 25 abr. 2007.

45. Nascimento FS, Helal DH. Expansão e interiorização das universidades federais: uma análise do processo de implementação do campus do Litoral Norte da Universidade Federal da Paraíba. Revista Gual 2015; 8(1):45-67.

Recebido: 26/10/2016

Aceito: 09/1/2017 